\title{
La aristocracia altomedieval: legados historiográficos y tendencias de investigación
}

Mariel Pérez

\section{(2) OpenEdition}

\section{Journals}

\section{Edición electrónica}

URL: http://journals.openedition.org/medievalista/263

DOI: 10.4000/medievalista.263

ISSN: 1646-740X

\section{Editor}

Instituto de Estudos Medievais - FCSH-UNL

\section{Referencia electrónica}

Mariel Pérez, «La aristocracia altomedieval: legados historiográficos y tendencias de investigación », Medievalista [En línea], 15 | 2014, Puesto en línea el 01 enero 2014, consultado el 01 mayo 2019. URL: http://journals.openedition.org/medievalista/263; DOI : 10.4000/medievalista.263

\section{(C) IEM}


Título: La aristocracia altomedieval: legados historiográficos y tendencias de investigación Autor: Mariel Pérez

Universidade: Universidad de Buenos Aires

Faculdade e Departamento / Unidade de Investigação: Instituto de Historia Antigua y Medieval, Facultad de Filosofía y Letras

Código Postal: 1002 Buenos Aires

Cidade: Buenos Aires

País: Argentina

Email: perez_mariel@yahoo.com.ar

Fonte: Medievalista [Em linha]. №15, (Janeiro - Junho 2014). Dir. José Mattoso. Lisboa: IEM.

Disponível em: http://www2.fcsh.unl.pt/iem/medievalista/

ISSN: $1646-740 \mathrm{X}$

Data recepção do artigo: 19 de Março de 2013

Data aceitação do artigo: 7 de Novembro de 2013

\section{Resumo}

El presente trabajo se propone realizar un recorrido a través de la historiografía sobre la aristocracia de la alta edad media, a fin de presentar un panorama general de los principales ejes de análisis, núcleos problemáticos y esquemas interpretativos que han signado el devenir de las investigaciones sobre el tema. Esta revisión pondrá de 
manifiesto que si bien la tradición historiográfica inaugurada por Marc Bloch y Georges Duby recogió en importante medida el legado de sus predecesores en cuanto a problemáticas y esquemas interpretativos, abriéndose líneas de investigación que profundizaron en torno a ciertos problemas clásicos como las transformaciones en las estructuras de parentesco, en las últimas décadas aparecieron nuevos intereses, perspectivas de interpretación y herramientas metodológicas que renovaron $\mathrm{y}$ revitalizaron este campo de estudios.

Palavras-chave: aristocracia, alta edad media, historiografía, tradiciones historiográficas, tendencias de investigación.

\section{Abstract}

The aim of this paper is to review the bibliography in use on aristocracy of the High Middle Ages in order to present its central topics of analysis, its core problems and the main interpretive schemes that are crucial in this field of studies. This review will show that although the historiographical tradition inaugurated by Marc Bloch and Georges Duby actually inherited the topics and schemes from their predecessors -which led them to go deeply into the study of classical questions such as the transformations of its family structures-, in the last decades a number of new problems on medieval aristocracy emerged, as well as new frameworks of interpretation and methodological tools that are renewing and revitalizing these studies.

Keywords: Aristocracy, High Middle Ages, Historiography, Historiographical Traditions, Research Trends. 


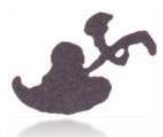

\section{La aristocracia altomedieval: legados historiográficos y tendencias de investigación}

\author{
Mariel Pérez
}

La nobleza ha sido uno de los grandes temas de estudio de los historiadores de la edad media. Concebida como grupo social definido por un estatuto jurídico particular transmisible por la sangre, como aristocracia guerrera, como clase feudal con poder sobre tierras y hombres, como estamento caracterizado por ciertos rasgos culturales y de comportamiento, como elite diversa y dinámica, de caracteres peculiares según la época y región, la nobleza ha sido objeto de una gran profusión de estudios que, desde diversos ámbitos historiográficos y académicos, abordaron la investigación desde una multiplicidad de problemáticas, enfoques, esquemas interpretativos y recursos metodológicos. Sin pretender un abordaje exhaustivo de tan vasta producción historiográfica, en el presente trabajo nos proponemos realizar un recorrido a través de los estudios sobre la nobleza del período altomedieval -con un recorte temporal centrado especialmente en los siglos IX y XI-, presentando los principales ejes de análisis y núcleos problemáticos que han signado el devenir de las investigaciones. Ante todo, haremos un repaso de aquellos trabajos clásicos como los de Marc Bloch y Georges Duby, que marcarían una senda ineludible en el desarrollo de los estudios sobre la nobleza. A continuación, presentaremos las líneas de investigación más destacadas dentro de la historiografía sobre la nobleza altomedieval en las últimas décadas, procurando perfilar la evolución de sus principales focos de interés y perspectivas interpretativas. 


\section{Los orígenes de una tradición: el legado de Marc Bloch y Georges Duby}

Todo estudio sobre la nobleza medieval tiene como referente ineludible a Marc Bloch. En 1939, en su obra La société féodal, el gran historiador francés establecía que para que una clase dominante ameritara la calificación de nobleza debía reunir dos condiciones: la posesión de un estatuto jurídico propio que materialice su superioridad y la perpetuación de este estatuto por la vía de la sangre. Así definida, la nobleza no habría hecho su aparición en el occidente medieval sino hasta el siglo XII. Desaparecidos los linajes nobles del Bajo Imperio y la época merovingia, en los primeros tiempos feudales la superioridad social no estaría vinculada a la sangre sino a la riqueza, el poder y el servicio al rey. Entre fines del siglo XII y principios del XIII se habría operado la transformación. La caballería dejaría de ser una situación de hecho, un género de vida, un privilegio personal, para convertirse en una prerrogativa heredada de los antepasados, vinculando así su estatuto al nacimiento ${ }^{1}$.

Por esos mismos años, sin embargo, los historiadores alemanes llegaban a conclusiones opuestas a la de Bloch. Gerd Tellenbach postulaba la existencia de una verdadera nobleza carolingia de carácter supralocal, la Reichsaristokratie, cuyas raíces podían remontarse, de acuerdo con Karl Ferdinand Werner, hasta el Bajo Imperio. La dificultad para encontrar los rasgos dinásticos de esta nobleza estaba vinculada, según Karl Schmid, con una forma de autoconciencia de los grupos familiares que enfatizaba los vínculos horizontales, a diferencia de la concepción linajística que prevalecería en los siglos posteriores ${ }^{2}$.

Los estudios sobre la aristocracia alemana no tendrían un efecto inmediato entre los historiadores franceses. Sin embargo, la publicación en 1960 del trabajo de Léopold Genicot sobre el condado de Namur reveló aspectos que ponían en entredicho la tesis de Bloch. En el Namurois del siglo XII, nobles y caballeros constituían dos estratos

\footnotetext{
${ }^{1}$ BLOCH, Marc - La société féodal. Vol. 2. Las clases et le gouvernement des hommes. Paris: Albin Michel, 1994 [1ra ed. 1939-1940], p. 395-460.

${ }^{2}$ Sobre la historiografía alemana vid. FREED, John - "Reflections on the Medieval German Nobility", American Historical Review, 91, 1986, pp. 553-575.
} 
sociales diferenciados. La caballería no había sido asimilada a la nobleza, como Bloch había supuesto ${ }^{3}$. Lo que Genicot evidenciaba era, como sintetizaba Georges Duby en 1961, que "la nobleza medieval es independiente de la caballería y anterior a ella; es una condición que se hereda de los antepasados, una cuestión de sangre"4. Y era esta constatación la que revelaría el verdadero alcance de los resultados obtenidos por los historiadores alemanes. La nobleza franca tenía raíces más tempranas que las que postulaba Bloch. Lo que se transformaba era la estructura de la familia.

Siguiendo las formulaciones pioneras de la historiografía alemana, Duby planteó que en época carolingia habría existido una verdadera nobleza, una nobleza de sangre, vinculada a los antepasados. La dificultad en reconstruir las líneas de parentesco residía en la estructura de la familia aristocrática y sus representaciones. Como ya lo había advertido Schmid, la familia aristocrática constituía un grupo de parientes débilmente cohesionado, con escasa jerarquización interna y limitada conciencia genealógica, dentro del cual las líneas de filiación derivadas del varón y la mujer operaban en igualdad de condiciones. Después del mil, por el contrario, la concepción familiar adquiriría un carácter dinástico, reflejando la cohesión del grupo de parientes, el reforzamiento de la filiación agnaticia y el establecimiento de pautas de sucesión basadas en la primogenitura masculina. Para Duby, estos cambios en la organización familiar estarían vinculados a las transformaciones operadas en el plano político. En el período carolingio, el monarca distribuía los cargos y honores entre los miembros de las familias nobles sin tener en cuenta la línea agnaticia ni la primogenitura. Se destacaba así la línea de filiación más prestigiosa y más cercana al entorno regio. Pero en torno al año mil los nobles comenzaron a adquirir poderes autónomos, convirtiendo los señoríos que habían detentado por delegación regia en patrimonio de la familia. La emergencia de formas políticas en las que la transmisión de la autoridad ya no dependía de la concesión del monarca sino de la sucesión hereditaria, supondría, en el plano del parentesco, un reforzamiento de la línea masculina y el consecuente advenimiento del linaje.

\footnotetext{
${ }^{3}$ GENICOT, Léopold - L'economie rurale namuroise au Bas Moyen Age, 1199-1429. Vol. 2. Les hommes, la noblesse. Louvain: Publications universitaires, 1960.

${ }^{4}$ DUBY, Georges - "La noblesse dans la France médiévale, une enquête à poursuivre", Revue Historique, 226, 1961, pp. 1-22, trad. cast. "La nobleza en la Francia medieval. Una investigación a proseguir", en Hombres y estructuras de la Edad Media. Madrid: Siglo XXI, 1978, 53-78, la cita en español, p. 58.
} 
Bajo estas nuevas premisas, se hacía necesario volver a interpretar las relaciones entre nobleza y caballería. Como hemos visto, de acuerdo con Duby en la alta edad media existía una nobleza de sangre que en principio estaba ligada a la casa real y luego se independizaría de ella, dando lugar a la alta nobleza feudal. En este marco, la caballería, si bien convertida en orden privilegiado, encargado durante el siglo $\mathrm{X}$ de proteger al pueblo de Dios y eximido, ya en el siglo XI, de la explotación señorial, era sin embargo un estrato social completamente ajeno a esta nobleza, cuyo prestigio sobrepasaba largamente a aquel de los caballeros. El acercamiento entre ambos niveles de la aristocracia se produciría en el siglo XIII, con la reducción del poder de la alta nobleza por parte de los reconstituidos príncipes territoriales y la elevación de los caballeros al estatuto de la nobleza con la vulgarización de los derechos señoriales ${ }^{5}$.

La obra de Duby, convertida en referencia historiográfica obligada, impulsaría los estudios sobre la nobleza en dos direcciones principales. Por un lado, el desarrollo de la caballería, sus orígenes y transformaciones, su organización, ideales, prácticas y códigos de comportamiento ${ }^{6}$. El otro gran eje que guiaría la investigación sobre la nobleza medieval sería el de sus estructuras de parentesco, que en las décadas siguientes entroncaría con el naciente interés en la historia de la familia y abrevaría de conceptos y modelos propios de las ciencias antropológicas ${ }^{7}$. La investigación se orientaría a

5 DUBY, Georges - "La noblesse dans la France médiévale...", op. cit.; "Structures de parenté et noblesse. France du Nord, XIe-XIIe siècles", Miscellanea medievalia in memoriam Jan Fredrik Niermeyer. Groningue: J-B. Wolters, 1967, pp. 149-165, trad. cast. "Estructuras de parentesco y nobleza en la Francia del norte en los siglos XI y XII", en Hombres y estructuras, op. cit., pp. 162-183; "Lignage, noblesse et chevalerie au XIIe siècle dans la région mâconnaise", Annales E.S.C., 27, 1972, pp. 803-823.

6 Algunos ejemplos destacados, DUBY, Georges - "Les origines de la chevalerie", en Ordinamenti militari in Occiente nell'alto Medioevo. Settimane di Studio del Centro Italiano di Studi sull'Alto Medioevo, XV. Spoleto: Centro Italiano di Studi sull'Alto Medioevo, 1968, pp. 739-761, trad. cast. "Los orígenes de la caballería", en Hombres y estructuras, op.cit., pp. 209-228; CONTAMINE, Philippe - La guerra en la Edad Media. Barcelona: Labor, 1984; PARISSE, Michel - Noblesse et chevalerie en Lorraine médiévale: Les familles nobles du XIe au XIIIe siècle. Nancy: Université de Nancy II, 1982; FLORI, Jean - L'idéologie du glaive. Préhistoire de la chevalerie. Genève: Librairie Droz, 1983; L'essor de la chevalerie, XIe-XIIe siècles. Genève: Librairie Droz, 1986; Chevaliers et chevalerie au Moyen Age. Paris: Hachette, 1998; QUINTANILLA RASO, María Concepción - Nobleza y caballería en la edad media. Madrid: Arco Libros, 1996; FLECKENSTEIN, Joseph - La caballería y el mundo caballeresco. Madrid: Siglo XXI, 2006; BARTHELÉMY, Dominique - La chevalerie. De la Germanie antique à la France du XIIe siècle. Paris: Fayard, 2007. En el ámbito ibérico, el interés por la caballería se proyecta hacia el estudio de los infanzones, véase por ejemplo PÉREZ DE TUDELA VELASCO, Ma. Isabel Infanzones y caballeros. Su proyección en la esfera nobiliaria castellano-leonesa. (Siglos IX-XI). Madrid: Universidad Complutense, 1979.

7 En los años setenta, la familia se había convertido en un tema sumamente en boga entre los historiadores: en 1972, la revista francesa Annales publicaba un número monográfico sobre el tema, 
demostrar la transformación de las vastas parentelas de la época carolingia, de estructuras laxas y horizontales, en linajes verticales y patrilineales ${ }^{8}$. Otro de los ámbitos problemáticos predilectos sería, sin duda, el de las estrategias matrimoniales de la nobleza, entendidas como parte esencial de sus mecanismos de contrucción de poder ${ }^{9}$.

Annales E.S.C., 4-5, 1972; en 1974, la École Française de Rome organizaba, bajo la dirección de G. Duby y J. Le Goff, un coloquio sobre familia y parentesco en el occidente medieval, AA.VV., Famille et parenté dans l'Occident médiéval, actes du colloque de Paris (6-8 juin 1974). Communications et débats présentés par Georges Duby et Jacques Le Goff, Rome: École Française de Rome, 1977; en 1977, el Centro Italiano di Studi sull'Alto Medioevo organizaba su Settimane di Studio sobre el matrimonio en la sociedad alto medieval, AA.VV. - Il matrimonio nella società altomedievale. Settimane di Studio del Centro Italiano di Studi sull'Alto Medioevo, XXIV. Spoleto: Centro Italiano di Studi sull'Alto Medioevo, 1977. Este desarrollo tendría una expresión de síntesis en BURGUIÈRE, André et al. - Histoire de la famille, Paris: Armand Colin, 1986, que abordaba la problemática desde una perspectiva interdisciplinaria. El desarrollo de los estudios sobre la familia y el parentesco en el ámbito del medievalismo estuvo nutrido y sustentado en gran medida por las contribuciones de las ciencias antropológicas, introduciéndose conceptos como filiación, alianza, endogamia, exogamia, o modelos de interpretación como el provisto por el estructuralismo de Claude Lévi-Strauss (vid. nota 9).

${ }^{8}$ BULLOUGH, Donald A. - "Early Medieval Social Groupings: The Terminology of Kinship", Past and Present, 45, 1969, pp. 3-18; GUERREAU-JALABERT, Anita - "Sur les structures de parenté dans l'Europe médiévale", Annales. E.S.C., XXXVI, 1981, pp. 1028-1049; BOUCHARD, Constance - "Family Structure and Family Consciousness among the Aristocracy in the Ninth to Eleventh Centuries", Francia, 14, 1986, pp. 639-658; TOUBERT, Pierre - "Le moment carolingien (VIIIe-Xe)", en A. Burguière et al. Histoire de la famille, Tome 2, Temps médiévaux: Orient, Occident. Paris: Armand Colin, 1986, pp. 333359; HENNEBICQUE, Régine [=LE JAN, R.] - "Structures familiales et politiques au IXe siècle: un groupe familial de l'aristocratie franque", Revue Historique, 538, 1981, pp. 289-333; AURELL, Martin "Le lignage aristocratique en Provence au XIe siècle", Annales du Midi, 98/174, 1986, pp. 149-163. En la historiografía hispana se destaca el trabajo pionero de Salvador de Moxó, quien retomando los aportes de Bloch y Genicot ofrecía la primera teoría global sobre la organización de la nobleza española y su evolución a lo largo de la edad media. Para Moxó, en España sería recién en el siglo XII que el estamento nobiliario alcanzaría su propio estatuto jurídico y se dotaría de una concepción familiar esencialmente dinástica, convirtiéndose así en lo que llama nobleza vieja. MOXÓ, Salvador de - "De la nobleza vieja a la nobleza nueva. La transformación nobiliaria castellana en la Baja Edad Media”, Cuadernos de Historia (Anexos de la revista Hispania), 3, 1969, pp. 1-210. En Portugal, introdujo el modelo de Duby para el análisis de la nobleza, MATTOSO, José - A nobreza medieval portuguesa. A família e o poder. Lisboa: Estampa, 1981; Ricos-homens, infanções e cavaleiros. A nobreza medieval portuguesa nos séculos XI e XII. Lisboa: Guimarães Editores, 1985.

${ }^{9}$ Toma los modelos de intercambio matrimonial propuestos por Lévi-Strauss, RUIZ DOMENEC, José Enrique - "Système de parenté et théorie de l'alliance dans la société catalane (env. 1000-env. 1240)", Revue Historique, 532, 1979, pp. 305-326; "Estrategias matrimoniales y sistemas de alianza entre Castilla y Cataluña en el siglo XII”, Hispania, 40/145, 1980, pp. 271-284. Desde la perspectiva del modelo de matrimonio cristiano, TOUBERT, Pierre - "La théorie du mariage chez les moralistes carolingiens", en Il matrimonio nella società altomedievale, op. cit., pp. 233-282; "L'institution du mariage chrétien, de l'Antiquité tardive à l'an mil", en Morfologie sociali e culturali in Europa fra tarda antichità e alto medioevo, Settimane di studio del Centro Italiano di Studi sull'Alto Medioevo. Spoleto: Centro Italiano di Studi sull'Alto Medioevo, 1998, pp. 503-553. Consideran el impacto de las normas eclesiásticas sobre las estrategias matrimoniales de la aristocracia, DUBY, Georges - Le Chevalier, la Femme et le Prêtre. Le Mariage dans la France féodale. Paris: Hachette, 1981; BOUCHARD, Constance - "Consanguinity and Noble Marriages in the Tenth and the Eleventh Centuries", Speculum, 56/2, 1981, pp. 268-287; GUERREAU-JALABERT, Anita - "Prohibitions canoniques et stratégies matrimoniales dans l'aristocratie médiévale de la France du Nord", en P. BONTE (dir.) - Épouser au plus proche. Inceste, prohibitions et stratégies matrimoniales autour de la Méditerranée. Paris: EHESS, 1994, pp. 293-319. Desde una perspectiva antropológica que vincula las prohibiciones canónicas con los mecanismos de acumulación material de la institución eclesiástica, GOODY, Jack - The Development of the Family and

Medievalista online № 15| Janeiro - Junho 2014 ( ) IEM - Instituto de Estudos Medievais 7 
Desde una mirada de conjunto, estas obras clásicas daban así inicio a una importante tradición historiográfica, dejando establecidas muchas de las problemáticas centrales que atravesarían los estudios sobre la aristocracia medieval en las décadas siguientes: la definición de la condición aristocrática, sus orígenes, sus estructuras de parentesco, su vinculación con el poder político y sus medios de legitimación como grupo social dominante.

\section{El devenir de las investigaciones en las últimas décadas: principales líneas de trabajo y perspectivas de interpretación}

El estudio de la aristocracia altomedieval ha experimentado un enorme desarrollo en las últimas décadas, convirtiéndose en eje rector de diversos programas colectivos de investigación, congresos y publicaciones que concentraron el trabajo de especialistas de distintas nacionalidades, disciplinas y ámbitos historiográficos. Dentro del vasto panorama de investigaciones que se han llevado a cabo en estos años, pueden señalarse algunos núcleos problemáticos de especial interés, como las estructuras de parentesco de los grupos aristocráticos, las relaciones entre la aristocracia laica y las instituciones eclesiásticas, los vínculos con la monarquía y el papel de la mujer en las estructuras y representaciones del poder. En su conjunto, este espectro de estudios lograría complejizar el estudio de la génesis de la aristocracia medieval, sus formas de organización y articulación interna y sus estrategias de reproducción social, en un diálogo entre las tradiciones heredadas y el aporte de nuevas problemáticas y perspectivas de análisis.

El problema de los orígenes de la nobleza como grupo social, tema que como hemos visto se había instalado tempranamente en la historiografía, continuó atrayendo un fuerte interés entre los medievalistas ${ }^{10}$. Sin embargo, una vez aceptadas las tempranas

Marriage in Europe. Cambridge: Cambridge University Press, 1983. Sus afirmaciones son puestas en cuestión por GUERREAU-JALABERT, Anita - "La parenté dans l'Europe médiévale et moderne; à propos d'une synthèse récente", L'homme, 29, 1989, pp. 69-93.

${ }^{10}$ En efecto, desde la década de 1960 hasta los últimos años, estas problemáticas siguieron siendo visitadas por los historiadores. Pueden mencionarse GENICOT, Léopold - "La Noblesse au Moyen Âge Dans L'ancienne "Francie": Continuité, Rupture ou Evolution?", Comparative Studies in Society and 
raíces de la nobleza postcarolingia -había sido Karl Ferdinand Werner quien planteara de forma pionera la vinculación de la nobleza medieval con las antiguas élites romanas $^{11}$, el eje de discusión tendería a desplazarse hacia los primeros siglos de la edad media, abordándose el problema en términos de herencia cultural, continuidad institucional o fusión de élites ${ }^{12}$. Ahora bien, si se asumía la continuidad de las élites desde los siglos temprano medievales, se presentaba el problema de explicar las transformaciones que estos grupos experimentaron a lo largo del período, lo que implicaba indagar sobre la naturaleza, las causas y la cronología de las mutaciones que afectaron a las élites entre los siglos VI y XI, mutaciones que les permitieron perpetuar su dominación social. Esta problemática fue de hecho el eje específico del encuentro Les Elites au Haut Moyen Age. Crises et Renouvellements, organizado por la École Française de Rome en 2004, con participación de especialistas dedicados a diversas regiones del ámbito europeo. Las respuestas que han ido ensayando los medievalistas se desarrollan en varios planos: las relaciones con la monarquía, la emergencia de los milites o los cambios en los modelos culturales ${ }^{13}$. Pero sobre todo, en el plano de las transformaciones de los sistemas de parentesco.

History, 5, 1, Oct. 1962, pp. 52-59; "Noblesse ou aristocratie. Des questions de méthode", Revue d'Histoire Ecclésiastique, LXXXV, 2, 1990, pp. 334-343; MARTINDALE, Jane - "The French Aristocracy in the Early Middle Ages: a Reappraisal", Past and Present, 75, 1977, pp. 5-45; BOUCHARD, Constance - "The Origins of the French Nobility: a Reassessment", American Historical Review, 86, 3, Jun. 1981, pp. 501-532. Para el ámbito hispano, la referencia clásica ha sido MOXÓ, Salvador de - "De la nobleza vieja a la nobleza nueva...", op. cit., que planteaba que los linajes nobiliarios no podían remontarse con datos genealógicos ciertos más allá del siglo XII. Esta idea sería puesta en tela de juicio por los resultados de las investigaciones posteriores fundadas en el trabajo prosopográfico, como el trabajo de CARLÉ, Ma. del Carmen - "Gran propiedad y grandes propietarios", Cuadernos de Historia de España, LVII-LVIII, 1973, pp. 1-224, donde se ponía de manifiesto que la llamada "nobleza vieja" podría rastrear sus orígenes a los magnates de los siglos X y XI. Asimismo, los tempranos orígenes de una aristocracia feudal se ponían de manifiesto en las monografías regionales, como MARTÍNEZ SOPENA, Pascual - La Tierra de Campos occidental. Poblamiento, poder y comunidad del siglo X al XIII. Valladolid: Institución Cultural Simancas, 1985.

${ }^{11}$ Una obra más reciente del autor, WERNER, Karl Ferdinand - Naissance de la noblesse. L'essor des élites politiques en Europe. Paris: Fayard, 1998.

${ }^{12}$ A modo de ejemplo, puede mencionarse el libro de síntesis de Joseph Morsel sobre la aristocracia medieval y la gran obra de Chris Wickham sobre la temprana edad media, que dedica un capítulo al estudio de las aristocracias, MORSEL, Joseph - L'aristocratie médiévale. La domination sociale en Occident (Ve- XVe siècle). Paris: Armand Colin, 2004; WICKHAM, Chris - Framing the Early Middle Ages. Europe and the Mediterranean, 400-800. Oxford: Oxford University Press, 2005, pp. 182-258.

${ }^{13}$ BOUGARD, François, FELLER, Laurent, LE JAN, Régine (eds.) - Les Elites au Haut Moyen Age. Crises et Renouvellements. Turnhout: Brepols, 2006, con colaboraciones de Laurent Feller, Bruno Dumézil, Flavia de Rubeis, Stefano Gasparri, Céline Martin, Philippe Depreux, Rosamond McKitterick, François Bougard, Régine Le Jan, Stuart Airlie, entre otros. Pueden mencionarse asimismo los trabajos de LE JAN, Régine - "Continuity and Change in the Tenth-Century Nobility"; NELSON, Janet - "Nobility 
Sobre la sólida base de sustento provista por una larga y profusa tradición historiográfica, en las últimas décadas se ha continuado profundizando en el estudio de las estructuras de parentesco de la nobleza, siempre en estrecha vinculación con las estrategias de poder desplegadas en el plano político, social y económico ${ }^{14}$. En líneas generales, los nuevos trabajos tomarían como referencia el modelo propuesto por Duby, reafirmando, ajustando o cuestionando la imagen que oponía las vastas parentelas cognaticias de la alta edad media a las estructuras linajísticas que emergieron después del mil y que traducían la consolidación y estabilización de la nobleza como grupo social superior. Desde un punto de vista interpretativo, deben destacarse las valiosas observaciones realizadas por Anita Guerreau-Jalabert, quien ha planteado que la aparición del linaje no habría implicado una transformación de las estructuras de parentesco a través del paso de una pauta de filiación cognaticia a otra agnaticia, sino que los cambios observados en la organización los grupos nobiliarios traducirían una adaptación de las representaciones y prácticas del parentesco a la territorialización de la aristocracia, es decir, a la estabilización de su poder en el ámbito espacial de un señorío que será transmitido de forma hereditaria al varón primogénito. Se constituirían así lo que la autora denomina "topolinajes", haciendo referencia a la línea de herederos de un determinado poder territorial. En este contexto, los rasgos que se han asociado con una conciencia de linaje -como la literatura genealógica, la aparición de escudos de armas o las transformaciones en el sistema antroponímico- se desarrollarían con el fin de ofrecer una imagen de la parentela que legitimara la transmisión hereditaria del castillo y el

in the Ninth Century"; REUTER, Timothy - "Nobles and Others: The Social and Cultural Expression of Power Relations in the Middle Ages", todos en A. DUGGAN (ed.) - Nobles and Nobility in Medieval Europe. Concepts, Origins, Transformations. Woodbridge: Boydell, 2000, pp. 53-68, 43-51, 85-98.

${ }^{14}$ LE JAN, Régine - Famille et pouvoir dans le monde franc (VIIe - Xe siècle). Essai d'anthropologie sociale. Paris: Publications de la Sorbonne, 1995; AURELL, Martin - Les noces du comte. Mariage et pouvoir en Catalogne (785-1213). Paris: Publications de la Sorbonne, 1995; "Pouvoir et parenté des comtes de la marche hispanique (801-911)", en R. Le Jan (ed.) - La Royauté et les élites dans l'Europe carolingienne. Villeneuve-d'Ascq: CRHENO, 1998, pp. 467-480; "Stratégies matrimoniales de l'aristocratie (IXe-XIIIe siècles)", en M. ROUCHE (ed.) - Mariage et sexualité au Moyen Age. Accord ou crise? Colloque de Conques 1998. Paris: Presses de l'Université de Paris-Sorbonne - Cultures et civilisations médiévales XXI, 2000, pp. 185-202; BOUCHARD, Constance - Those of My Blood: Constructing Noble Families in Medieval Francia. Philadelphia: University of Pennsylvania Press, 2001; DUHAMEL-AMADO, Caudie - "Les pouvoirs et les parents autour de Béziers (980-1100)", Annales du Midi, 102, 1990, pp. 309-317; L'aristocratie languedocienne du Xe au XIIe siècle. Genèse des lignages méridionaux. Toulouse: CNRS-Université de Toulouse-Le Mirail, 2001; Genèse des lignages méridionaux: potraits de familles. Toulouse: CNRS-Université de Toulouse-Le Mirail, 2007. La actualidad de la problemática se pone de manifiesto, por ejemplo, con la reciente aparición de un dossier monográfico sobre Légitimation et lignage en el medioevo ibérico en la revista e-Spania, 11, juin 2011. 
poder territorial que éste encarnaba. Así concebido, por tanto, el linaje no supondría la configuración de un nuevo sistema de parentesco sino el desarrollo de determinadas prácticas de transmisión y legitimación del poder en el marco de unas estructuras parentales cognaticias ${ }^{15}$.

Por otra parte, el modelo presentaría algunas dificultades al ser extrapolado a regiones ajenas al ámbito que sustentó su enunciación original. Debe hacerse referencia en este sentido a la historiografía ibérica. Para el norte hispánico, los estudios han revelado que, a diferencia de Francia, los grupos aristocráticos habrían presentado durante largo tiempo una configuración familiar cognaticia, horizontal, poco cohesionada y con escasa profundidad genealógica, en la que los bienes, el poder y el prestigio social se transmitían indistintamente a través de las líneas de filiación derivadas del varón y la mujer, si bien, como advertía Pascual Martínez Sopena, la atribución de los títulos condales mostraba en la práctica una tendencia agnaticia. Los rasgos de linaje empezarían a aflorar en el noroeste hispánico recién hacia el siglo XII, consolidándose las pautas de agnación y primogenitura a fines del siglo XIV con la constitución de los primeros mayorazgos ${ }^{16}$. En Portugal, este modelo, introducido en la historiografía por

\footnotetext{
${ }^{15}$ GUERREAU-JALABERT, Anita - "La parenté dans l'Europe médiévale et moderne...", op. cit., "El sistema del parentesco medieval: sus formas (real/espiritual) y su dependencia respecto a la organización del espacio", en R. PASTOR (comp.) - Relaciones de poder, de producción y parentesco en la Edad Media y Moderna. Madrid: CSIC, 1990, pp. 85-106.

${ }^{16}$ PORTELA, Ermelindo, PALLARES, Ma. del Carmen - "Elementos para el análisis de la aristocracia altomedieval de Galicia: parentesco y patrimonio", Studia historica. Historia medieval, V, 1987, pp. 1732; MARTÍNEZ SOPENA, Pascual - "Parentesco y poder en León durante el siglo XI. La 'casata' de Alfonso Díaz", Studia historica. Historia medieval, V, 1987, pp. 33-88; "El conde Rodrigo de León y los suyos. Herencia y expectativa de poder entre los siglos X y XII", en R. Pastor (comp.) - Relaciones de poder, op. cit., pp. 51-84; BECEIRO PITA, Isabel, CÓRDOBA DE LA LLAVE, Ricardo - Parentesco, poder y mentalidad. La nobleza castellana. Siglos XII-XV. Madrid: CSIC, 1990; PALLARES, Ma. del Carmen, PORTELA, Ermelindo - "Aristocracia y sistema de parentesco en la Galicia de los siglos centrales de la Edad Media. El grupo de los Traba”, Hispania, 185, 1993, pp. 823-840; BARTON, Simon - The aristocracy in twelfth-century León and Castile. Cambridge: Cambridge University Press, 1997; TORRES SEVILLA, Margarita - Linajes nobiliarios en León y Castilla. Siglos IX-XIII. Salamanca: Junta de Castilla y León, 1999; "Los linajes leoneses en búsqueda de un sistema estable (siglos X-XII): el parentesco como base del poder nobiliario", en F. SABATÉ y J. FARRÉ (coord.) - El poder a l'Edad Mitjana. Reunió científica. VIII Curs d'Estiu Comtat d'Urgell (Balaguer, 9-11 de juliol de 2003). Lleida: Pagès, 2004, pp. 57-92; ÁLVAREZ BORGE, Ignacio - "La nobleza castellana en la edad media: familia, patrimonio y poder", en J. I. de la IGLESIA DUARTE (ed.) - La familia en la Edad Media, XI semana de estudios medievales, Nájera, 31 de julio al 4 de agosto de 2000. Logroño: IER, 2001, pp. 221-252; CALLEJA PUERTA, Miguel - El conde Suero Vermúdez, su parentela y su entorno social. La aristocracia leonesa en los siglos XI y XII. Oviedo: KRK Ediciones, 2001.
} 
José Mattoso $^{17}$, sería revisado por algunos de sus discípulos, poniéndose de manifiesto, como señalara José Augusto de Sottomayor-Pizarro, que la adopción de esquemas interpretativos construidos a partir de la nobleza francesa habría llevado a conclusiones sobre el comportamiento o la evolución de la nobleza poco adecuadas para la realidad peninsular $^{18}$. El propio Mattoso advertía recientemente que el modelo formulado por Duby debía constituir un esquema de referencia y no una norma de evolución social, en tanto los nuevos aportes de la historiografía portuguesa evidenciaban que los grupos aristocráticos habrían utilizado estrategias diversas para reproducir su posición social y evitar la ruina de la parentela ${ }^{19}$.

A su vez, los estudios recientes han ido complejizando el problema del parentesco, adentrándose en nuevos cauces de investigación que, si bien seguían orbitando en torno a los grandes ejes del linaje y el matrimonio, agregaban nuevas facetas al análisis. Dentro de este marco, una de las nuevas líneas de investigación se focalizó en las distintas formas de transmisión del patrimonio familiar y sus implicancias sociales y económicas. El problema ha sido abordado por un amplio grupo de historiadores, cuyos trabajos se concentran especialmente en las colaboraciones recogidas en tres coloquios internacionales organizados por la École Française de Rome, en los que participaron destacados especialistas de los siglos altomedievales, como Régine Le Jan, Laurent Feller, François Bougard, Claudie Duhamel Amado, Geniviève Bührer-Thierry, Martin Aurell, Lluis To Figueras, Hans-Werner Goetz, Wendy Davies, Janet Nelson, Cristina La Rocca, Claudio Azzara y Stefano Gasparri, entre otros. El primero de estos

\footnotetext{
${ }^{17}$ MATTOSO, José - A nobreza medieval portuguesa, op.cit.; Ricos-homens, infanções e cavaleiros, op. cit.

${ }^{18}$ SOTTOMAYOR-PIZARRO, José Augusto de - "Linhagem e estruturas de parentesco", e-Spania [En línea], 11, juin 2011. DOI: 10.4000/e-spania.20366.

19 Vid. MATTOSO, José - "The Medieval Portuguese Nobility", en J. MATTOSO (dir.) - The Historiography of Medieval Portugal, c. 1950-2010. Lisboa: Instituto de Estudos Medievais, 2011, pp. 408-409. Deben mencionarse, si bien exceden el marco cronológico propuesto para el presente trabajo, dos importantes líneas investigación que - llevadas a cabo por sendos discípulos de Mattoso- contribuirían a la revisión del modelo. En primer lugar, José Augusto de Sottomayor Pizarro demostró que la sucesión hereditaria unilineal estaba lejos de ser la regla y que el objetivo de mantener la herencia intacta solía lograrse evitando que los segundos hijos contrajeran matrimonio, SOTTOMAYOR-PIZARRO, José Augusto de - Linhagens medievais portugueses: genealogías e estratégias, (1279-1325). Porto: Universidade Moderna, 1999. Por su parte, Luís Filipe Oliveira embistió contra la idea de que el reclutamiento de caballeros para las órdenes militares hubiera privilegiado a los iuvenes - hijos menores de los linajes excluidos de la sucesión política-, mostrando que la mayor parte de los miembros de estas órdenes tenían orígenes no nobles, OLIVEIRA, Luís Filipe - A Coroa, os Mestres e os Comendadores. As Ordens Militares de Avis e de Santiago (1330-1449). Faro: Universidade do Algarve, 2009.
} 
coloquios, Transferts patrimoniaux en Europe occidentale, se llevó a cabo en 1999 y abordaba el problema de la circulación de bienes en el seno de la familia, ampliando las perspectivas sobre la jerarquización en el interior de la familia aristocrática, la dinámica de los patrimonios familiares y las coacciones ejercidas por la parentela en las transacciones patrimoniales ${ }^{20}$. Un año después se llevaría a cabo la reunión Dots et douaires dans le haut Moyen Âge, en el que se intentaba trazar la evolución de las prácticas y normas que dominaron las transferencias matrimoniales entre los siglos VI y $\mathrm{XI}^{21}$. Así, se abordaban problemas tales como el tipo de bienes implicados en estas transferencias, las diferencias entre los bienes aportados por la familia del esposo y la esposa, la importancia material de esas donaciones y cómo afectaban el patrimonio global de cada familia, el grado de control real que adquiría la mujer sobre esos bienes o las distintas funciones que cumplían para las familias de los distintos cónyuges. Finalmente, dentro de la temática que vincula estructuras familiares y patrimonio se presenta también el problema de las donaciones a las instituciones eclesiásticas y su incidencia en la reproducción material de los grupos aristocráticos. Éste ha sido el tema del coloquio Salvarsi l'anima, perpetuare la famiglia, celebrado en Padova en el año 2002, en el que se intentaba superar a partir de estudios de diverso carácter y perspectivas la clásica antinomia entre la salvación del alma a través de las donaciones piadosas a iglesias y monasterios y la perpetuación del patrimonio familiar ${ }^{22}$. Esta línea de estudios recogía así el legado sembrado en los años ochenta por la historiografía anglosajona, que reexaminaba el problema de las donaciones piadosas a partir del

\footnotetext{
${ }^{20}$ Transferts patrimoniaux en Europe occidentale, VIIIe-Xe siècles, Actes de la table ronde de Rome, 6, 7 et 8 mai 1999, Rome, 1999, en Mélanges de l'École Française de Rome, Moyen Âge, tome 111, 2, 1999. Entre las colaboraciones ofrecidas en este coloquio, cabe destacar el estudio de Régine Le Jan, quien examina el problema de la libertad del individuo frente a la parentela en el mundo franco y pone en cuestión la validez de la noción de propiedad en una sociedad regulada por la reciprocidad, LE JAN, Régine - "Malo ordine tenent. Transferts patrimoniaux et conflits dans le monde franc (VIIe- Xe siècle)", op. cit., pp. 951-972 Por su parte, Claudie Duhamel Amado focaliza su análisis en la Gothie, planteando que, mientras en la alta edad media los individuos poseían una libertad real para realizar transacciones, hacia el 1030 se habría acentuado la presión de los parientes sobre las tierras familiares, imponiéndose un mayor control de la parentela sobre las transacciones, DUHAMEL AMADO, Claudie - "La circulation des biens à l'intérieur de la famille aristocratique de la Gothie au Xe siècle", op. cit., pp. 895-910.

${ }^{21}$ BOUGARD, François, FELLER, Laurent, LE JAN, Régine (eds.) - Dots et douaires dans le haut Moyen Age. Colloque de Lille et Valenciennes 2000. Rome: Collection de l'École Française de Rome, 2002.

${ }^{22}$ BOUGARD, François, LA ROCCA, Cristina, LE JAN, Régine (dir.) - Sauver son âme et se perpétuer: Transmission du patrimoine et mémoire au haut moyen âge. Roma: École française de Rome, 2005. Para el ámbito ibérico, DAVIES, Wendy - Acts of Giving: Individual, Community and Church in Tenth-Century Christian Spain. Oxford: Oxford University Press, 2007.
} 
modelo de don-contradon propuesto por Marcel Mauss, y abría nuevas facetas de análisis en torno a la relación entre nobleza, parentesco e Iglesia ${ }^{23}$.

Esta atención en el problema de las donaciones piadosas es a su vez reveladora del creciente interés que adquirían las relaciones entre la aristocracia medieval y las instituciones eclesiásticas, como lo ponen de manifiesto para Francia los estudios de Eliana Magnani, Florian Mazel y Géniviève Bührer-Thierry, o para España los de Pascual Martínez Sopena y Carlos Reglero de la Fuente. En líneas generales, los trabajos enfocados en el tema han tendido a matizar la clásica oposición entre aristocracia e Iglesia, poniendo de relieve la compleja imbricación de los vínculos que se establecieron entre ambos estamentos en la alta edad media y llamando la atención sobre los beneficios que muchas veces esas relaciones implicaron para los laicos. Desde esta perspectiva se han abordado cuestiones como los conflictos entre clérigos y laicos, el papel desempeñado por los llamados "monasterios particulares" en la construcción del poder aristocrático y su devenir tras la reforma eclesiástica, las relaciones de la nobleza con Cluny o las posteriores vinculaciones entre las familias aristocráticas y órdenes monásticas como la del Císter ${ }^{24}$.

${ }^{23}$ Dos obras de referencia obligada, WHITE, Stephen - Custom, Kinship and Gifts to Saints: The “Laudatio Parentum” in Western France, 1050-1150. Chapel Hill: University of North Carolina Press, 1988; ROSENWEIN, Barbara - To be the Neighbor of Saint Peter. The Social Meaning of Cluny's Property, 909-1049. Ithaca-Londres: Cornell University Press, 1989.

24 La historiografía hispana es sumamente rica al respecto: MARTÍNEZ SOPENA, Pascual "Monasterios particulares, nobleza y reforma eclesiástica en León entre los siglos XI y XII", en AA.VV. Estudios de historia medieval. Homenaje a Luis Suárez Fernández. Valladolid: Universidad de Valladolid, 1991, pp. 323-331; "Fundaciones monásticas y nobleza en los reinos de Castilla y León en la época románica”, en J. A. GARCÍA DE CORTÁZAR (coord.) - Monasterios románicos y producción artística. Aguilar de Campoo: Fundación de Santa María la Real, 2003, pp. 35-62; "Aristocracia, monacato y reformas en los siglos XI y XII", en AA.VV. - El monacato en los reinos de León y Castilla (siglos VII-XIII), X Congreso de Estudios Medievales 2005, Ávila: Fundación Sánchez Albornoz, 2007, pp. 67-100; REGLERO DE LA FUENTE, Carlos - Cluny en España: los prioratos de la provincia y sus redes sociales (1073- ca. 1279). León: Centro de Estudios e Investigación "San Isidoro", 2008; COELHO, Maria Filomena - Expresiones del poder feudal: el Císter femenino en León (siglos XII y XIII). León: Universidad de León, Secretariado de Publicaciones, 2006; ALONSO ÁLVAREZ, Raquel - "Los promotores de la orden del Císter en los reinos de Castilla y León: familias aristocráticas y damas nobles", Anuario de Estudios Medievales, 37/2, 2007, pp. 653-710; CALDERÓN MEDINA, Inés - "El impulso nobiliario a la expansión del Císter en el Reino de León. La parentela de Ponce de Cabrera en los monasterios de Santa María de Moreruela y San Esteban de Nogales", Medievalismo: Boletín de la Sociedad Española de Estudios Medievales, 18, 2008, pp. 341-374. Por otra parte, deben destacarse dos grandes obras sobre la evolución de las relaciones entre la aristocracia y las instituciones eclesiásticas en Provenza, MAGNANI SOARES CHRISTEN, Eliana - Monastères et aristocratie en Provence Milieu du X - debut du XII siècle. Münster - Lit-Verlag, 1999; MAZEL, Florian - La noblesse et l'Église en Provence, fin Xe-début XIVe siècle. L'exemple des familles d'Agoult-Simiane, de Baux et de Marseille. 
Por su parte, la dinámica de las relaciones entre los grupos aristocráticos y la monarquía, tema cuyo referente tradicional había sido trabajo clásico de Ganshof sobre las instituciones feudo-vasalláticas, también comenzaría a ser objeto de nuevas reflexiones. Desde un enfoque que se alejaba del nominalismo que había dominado los estudios tradicionales, comenzó a desarrollarse una nueva corriente de estudios que consideraban el feudo en un sentido amplio y lo vinculaban con las estructuras políticas y económicas de la sociedad medieval. Comenzaron asimismo a estudiarse distintos aspectos de las relaciones entre nobleza y monarquía: las prácticas y concepciones del poder, los conflictos entre reyes y nobles, el papel del parentesco en la articulación de las relaciones de poder y dependencia. A su vez, se ponía de manifiesto que la propia jerarquización de la aristocracia se hallaba definida en una importante medida por la relación que los diversos miembros de la elite sostenían con el monarca, situación que podía modificarse de acuerdo con las circunstancias políticas ${ }^{25}$. Por su parte, en el ámbito ibérico uno de los puntos de reflexión orbitó en torno al grado de dependencia de la nobleza respecto de la monarquía, tomándose como referencia implícita de la discusión la idea de Claudio Sánchez Albornoz sobre la excepcional fortaleza del poder regio en España $^{26}$.

Paris: CTHS, 2002. Diferentes aspectos de los vínculos entre aristocracia e Iglesia, LA ROCCA, Cristina - "La reine et ses liens avec les monastères dans le royaume d'Italie", en LE JAN, R. (ed.) - La Royauté et les élites, op. cit., pp. 269-284; FELLER, Laurent - "Les politiques des familles aristocratiques à l'égard des églises en Italie centrale (IXe-XIe) siècles", TO FIGUERAS, Lluis - "Fondations monastiques et mémoire familiale en Catalogne (IXe - XIe siècle)", BUHRER THIERRY, Geniviève - "Des evêques, des clercs et leurs familles dans la Bavière des VIIIe - IXe siècle", todos en F. BOUGARD, C. LA ROCCA, R. LE JAN, (dir.) - Sauver son âme et se perpétuer, op. cit., pp. 265-292, 293-329, 239-264; BUHRER THIERRY, Geneviève - "Entre implantation familiale et patrimoine ecclésiastique: les lieux de pouvoir des évêques de Freising au IXe siècle", en Ph. DEPREUX, F. BOUGARD, R. LE JAN (éds.) Les élites et leurs espaces: mobilité, rayonnement, domination (VIe-Xe s.). Turnhout: Brepols, 2007, pp. 299-318; MAZEL, Florian - "Amitié et rupture de l'amitié. Moines et grands laïcs provençaux au temps de la crise grégorienne (milieu XIe-milieu XIIe siècle)", Revue historique, 307, 2005, pp. 53-95.

${ }^{25}$ Entre las obras colectivas enfocadas hacia los vínculos políticos y la relación entre nobleza y monarquía, BOURNAZEL, Eric, POLY, Jean-Pierre (dir.) - Les féodalités. Histoire générale des systèmes politiques. Paris: PUF, 1998 ; el coloquio de Conques, en BONNASSIE, Pierre (ed.) - Fiefs et Féodalité dans l'Europe Méridonale (Italie, France du Midi, Péninsule Ibérique) du X au XIII siècle. Toulouse, CNRS- Universidad de Toulouse-Le Mirail, 2002; LE JAN, Régine (ed.) - La Royauté et les élites, op. cit.; PÉREZ, Joseph, AGUADÉ NIETO, Santiago (ed.) - Les origines de la féodalité. Hommage à Claudio Sánchez-Albornoz. Madrid: Casa de Velázquez, 2000. Una tesis de doctorado que profundiza en el análisis de la fidelidad, el juramento, el vasallaje y el feudo en el Languedoc, DÉBAX, Hélène - La féodalité languedocienne, $\mathrm{XI}^{\mathrm{e}}$-XII ${ }^{\mathrm{e}}$ siècles. Serments, hommages et fiefs dans le Languedoc des Trenca vel. Toulouse: Presses Universitaires du Mirail, 2003.

${ }^{26}$ ISLA FREZ, Amancio - Realezas hispánicas del año mil. Santiago de Compostela: Ediciones do Castro, 1999; MARTÍNEZ SOPENA, Pascual - "Reyes, condes e infanzones: aristocracia y alfetena en el 
Otro de los grandes ejes que ha guiado la investigación sobre la aristocracia altomedieval en los últimos años ha sido el del papel de las mujeres de la nobleza. Desde su emergencia en la década del setenta, impulsada principalmente por especialistas inglesas y norteamericanas, los estudios sobre la mujer alcanzaron un notable desarrollo, penetrando en distintos ámbitos historiográficos e introduciendo nuevas temáticas y perspectivas de análisis. Esto entrañó, especialmente en el espacio anglosajón, pero crecientemente en todo el ámbito europeo, la inclusión de las mujeres -y sobre todo de las mujeres de la nobleza- como problemática de investigación en el campo de la historia medieval. Los estudios en torno a la mujer aristocrática se han orientado en dos direcciones principales. Por un lado, los historiadores se han abocado al estudio de las mujeres en relación con las estructuras de poder de la alta edad media, tratando de dilucidar su papel en el ejercicio y transmisión del poder, su capacidad en la posesión y disposición efectiva de la tierra, o su rol en las estrategias familiares de poder $^{27}$. Por otro, se han abordado las representaciones elaboradas sobre la mujer y el

reino de León”, en AA.VV. - Ante el milenario del reinado de Sancho el Mayor: un rey navarro para España y Europa, XXX Semana de Estudios Medievales, Estella, 14 a 18 de julio de 2003. Pamplona: Gobierno de Navarra, 2004, pp. 109-154; "Reyes y nobles en León (ca. 860-1160)", en AA.VV. Monarquía y sociedad en el reino de León, de Alfonso III a Alfonso VII. León: Centro de Estudios e Investigación "San Isidoro", 2008, pp. 149-200; CALLEJA PUERTA, Miguel - El conde Suero Vermúdez, op. cit.; DOUBLEDAY, Simon R. - Los Lara: Nobleza y monarquía en la España medieval, Madrid: Turner, 2004; MÍNGUEZ FERNÁNDEZ, José María - "Pervivencia y transformaciones de la concepción y práctica del poder en el Reino de León (siglos X y XI)", Studia Historica. Historia Medieval, 25, 2007, pp. 15-65; CALDERÓN MEDINA, Inés - Cum magnatibus regni mei. La nobleza y la monarquía leonesa durante los reinados de Fernando II y Alfonso IX de León (1157-1230). Madrid: CSIC, 2012. Para Portugal, VIOLANTE BRANCO, Maria-João - "Portugal no Reino de Leão. Etapas de uma relação (866-1179)", en AA.VV. - El reino de León en la Alta Edad Media, VII, León: Centro de Estudios e Investigación "San Isidoro", 1995, pp. 533-625.

${ }^{27}$ Pueden mencionarse WERNER, Karl Ferdinand - "Les femmes, le pouvoir et la transmission du pouvoir", en M. Rouche y J. Heuclin (ed) - La femme au Moyen Age. Maubeuge: Publications de la ville de Maubeuge, 1990, pp. 365.377; TO FIGUERAS, Luis - "Les femmes dans la société catalane des IXeXIe siècles", en Les Femmes dans l'histoire de la société méditerranéenne. 66e Congrès de la Fédération historique du Languedoc-Roussillon (Narbonne, 1994). Montpellier: Fédération Historique du Languedoc Méditerranéen, 1995, pp. 51-65; LA ROCCA, Cristina - "Pouvoirs des femmes, pouvoir de la loi dans l'Italie lombarde", en S. LEBECQ, A. DIERKENS, R. LE JAN, J.-M. SANSTERRE (eds.) - Femmes et pouvoirs des femmes à Byzance et en Occident (VIe - XIe). Lille, CRHENO, 1999, pp. 37-50; EVERGATES, Thomas (ed.) - Aristocratic Women in Medieval France. Philadelphia: University of Pennsylvania, 1999; HENRIET, Patrick - "Deo votas. L'Infantado et la fonction des infantes dans la Castille et le León des X ${ }^{\mathrm{e}}-\mathrm{XII}^{\mathrm{e}}$ siècles”, en P. HENRIET, A. M. LEGRAS (comps.) - Au cloître et dans le monde. Femmes, hommes et sociétés ( $\mathrm{IX}^{\mathrm{e}}-\mathrm{XV}^{\mathrm{e}}$ siècle). Mélanges en l'honneur de Paulette l'HermiteLeclercq. Paris: Presses de l'Université de Paris-Sorbonne, 2000, pp. 189-203; LE JAN, Régine "L'épouse du comte du IXe au XIe siècle: transformation d'un modèle et idéologie du pouvoir", en Femmes, pouvoir et société dans le haut Moyen Age. Paris: Picard, 2001, pp. 65-73; SANTINELLI, Emmanuelle - Des Femmes éplorées? Les veuves dans la société aristocratique du haut Moyen Âge. Villeneuve d'Ascq: Presses Universitaires du Septentrion, 2003; BÜHRER-THIERRY, Geniviève - "Les femmes et la terre. Transmission des patrimoines et stratégies sociales des familles dans l'aristocratie du 
proceder femenino, en tanto instrumento de legitimación política y social de las élites altomedievales $^{28}$.

Para finalizar, cabe apuntar que en las últimas décadas el desarrollo de los estudios nobiliarios estuvo acompañado por la aparición de nuevas propuestas metodológicas que se presentan como enormemente prometedoras para el estudio de la aristocracia del período altomedieval. Pueden destacarse los logros que se han obtenido en el ámbito ibérico a través de los estudios centrados en la biografía, entre los que se destacan los trabajos de Miguel Calleja sobre el conde asturiano Suero Vermúdez y de Ma. del Carmen Pallares sobre la aristócrata gallega Ilduara ${ }^{29}$. Lejos de la biografía convencional, estos trabajos sitúan a sus protagonistas en la red de relaciones sociales en la que se insertaban, intentando "dar cuenta de los diversos modos de integración del individuo en el medio social" ${ }^{\prime 3}$. Otro recurso metodológico que está demostrando interesantes resultados en el abordaje de la nobleza es el análisis antroponímico, que permite acercarnos a las estructuras de parentesco de la aristocracia laica, las formas de conciencia familiar y las representaciones en torno a la transmisión y legitimación del poder. Se ha puesto de manifiesto, en efecto, que la onomástica constituía un elemento fundamental de la herencia nobiliaria, susceptible de iluminar diversos aspectos de la identificación del individuo como integrante de un grupo de poder ${ }^{31}$. Finalmente, deben

monde carolingien (VIIe-Xe siècles)", Bulletin du centre d'études médiévales d'Auxerre [En ligne], 8, 2004, DOI: 10.4000/cem.858; NELSON, Janet - Courts, Elites and Gendered Power in the Early Middle Ages. Aldershot: Ashgate-Variorum, 2007; PALLARES, Ma. del Carmen - Ilduara, una aristócrata del siglo X. La Coruña: Sada, 1998; PALLARES, Ma. del Carmen, PORTELA, Ermelindo - La reina Urraca. San Sebastián: Nerea, 2006; ISLA FREZ, Amancio - "Reinas hispanas de la Alta Edad Media", PALLARES, Ma. del Carmen - "Grandes señoras en los siglos IX y X” y RODRÍGUEZ LÓPEZ, Ana "La estirpe de Leonor de Aquitania: estrategias familiares y políticas en los siglos XII y XIII", todos en I. MORANT (coord.) - Historia de las mujeres en España y América Latina. Madrid: Cátedra, 2005, pp. 399-422, 423-442, 549-568. Se ha hecho referencia asimismo a los vínculos de las mujeres nobles con los centros monásticos, vid. nota 24.

${ }^{28}$ BRUBAKER, Leslie, SMITH, Julia (ed.) - Gender in the Early Medieval World. East and West, 300900. Cambridge: Cambridge University Press, 2004; SANTINELLI, Emmanuelle - "Les femmes et la mémoire: le rôle des comtesses dans la Francie occidentale du XI ${ }^{\mathrm{e}}$ siècle", en Sauver son âme et se perpétuer, op. cit., pp. 459-484; LA ROCCA, Cristina (a cura di) - Agire da donna. Modelli e pratiche di rappresentazione (secoli VI-X). Turnhout: Brepols, 2007.

29 PALLARES, Ma. del Carmen - Ilduara, una aristócrata del siglo X, op. cit.; CALLEJA PUERTA, Miguel - El conde Suero Vermúdez, op. cit. Una reflexión general sobre la revitalización del género biográfico en la historiografía, PEÑA PÉREZ, Francisco Javier - "El renacimiento de la biografía", Edad Media. Revista de Historia, 5, 2002, pp. 39-66.

${ }^{30}$ CALlEJA PUERTA, Miguel - El conde Suero Vermúdez, op. cit., p. 32.

${ }^{31}$ MAZEL, Florian - "Noms propres, dévolution du nom et dévolution du pouvoir dans l'aristocratie provençale (milieu Xe-fin XIIe siècle)", Provence historique, LIII, 2003, pp. 131-174. Para el reino 
tomarse en consideración los aportes provenientes del ámbito de la arqueología, que abren nuevos caminos en el abordaje de los problemas relativos a la diferenciación social y la identificación de los elementos materiales y simbólicos de la construcción del estatus y el poder.

\section{Conclusiones}

Este recorrido a través de los estudios sobre la aristocracia altomedieval nos invita a plantear algunas conclusiones. Ante todo, debe enfatizarse el importante papel que ejercería la obra de autores como Bloch o Duby en el desarrollo posterior de las investigaciones, dejando delineados ciertos ejes problemáticos que continuarían ejerciendo gran atracción entre los historiadores, como el problema de los orígenes de la nobleza y las transformaciones que experimentó en los siglos alto y pleno medievales, especialmente en el plano de las estructuras de parentesco. En las últimas décadas, el parentesco continuaría siendo uno de los temas que mayor atención atrajo entre los historiadores dedicados a la nobleza altomedieval, permaneciendo como modelo de referencia en la historiografía el clásico esquema que oponía parentela y linaje como gramática interpretativa básica de los cambios en las formas de organización interna de los grupos aristocráticos. Sin embargo, esta interpretación sobre las transformaciones en el parentesco ha sido revisada, bien desde un punto de vista conceptual, bien desde su

leonés, MARTÍNEZ SOPENA, Pascual - "La antroponimia leonesa. Un estudio del Archivo Catedral de León (876-1200)", en P. MARTÍNEZ SOPENA (coord.) - Antroponimia y sociedad. Sistemas de identificación hispano-cristianos en los siglos IX a XIII. Valladolid: Universidad de Valladolid, 1995, pp. 155-180; "La evolución de la antroponimia de la nobleza castellana entre los siglos XII y XIV", AA.VV. - Poder y sociedad en la Baja Edad Media hispánica: estudios en homenaje al profesor Luis Vicente Díaz Martín. Valladolid: Universidad de Valladolid, 2002, pp. 461-480; TORRES SEVILLA, Margarita "Antroponimia nobiliaria leonesa durante el siglo X: las casas de Cea y Saldaña”, en M. C. AGUILERA CASTRO (coord.) - Vida Cotidiana de la España Medieval, Actas del VI Curso de Cultura Medieval, Aguilar de Campoo, 1994. Madrid: Fundación Santa María La Real- Centro de Estudios del Románico, 1998, pp. 231-244; CALDERÓN MEDINA, Inés - "La antroponimia de la nobleza leonesa plenomedieval. Un elemento de construcción de identidad y memoria nobiliaria", Miscelánea medieval murciana, 35, 2011, 67-88. Para Cataluña, MARTÍNEZ I TEIXIDÓ, Lydia - "La antroponimia nobiliaria del condado de Pallars en los siglos XI y XII", en P. MARTÍNEZ SOPENA (coord.) - Antroponimia y sociedad, op. cit., pp. 327-350; TO FIGUERAS, Lluis - "Anthroponymie et pratiques succésorales. À propos de la Catalogne, Xe-XIIe siècle”, in M. BOURIN, J.-M. MARTIN y F. MENANT (ed.) L'anthroponymie, document de l'histoire sociale des mondes Méditerranéens Médiévaux (Actes du colloque de Rome, 6-8 octobre 1994). Roma-Paris: École Française de Rome-Palais Farnèse, 1996, pp. $432-433$. 
aplicación práctica, sobre todo en el ámbito ibérico. Además, se ha enriquecido el abordaje del problema, incorporando al análisis aspectos como la circulación de los bienes en el interior de los grupos familiares o el papel de las mujeres en la transmisión del poder y los patrimonios fundiarios. Han aparecido a su vez nuevos ejes temáticos, como los vínculos de los grupos aristocráticos con la Iglesia, y se han revisitado temas clásicos a través de otros prismas, como la dinámica de las relaciones entre la nobleza y la monarquía. Por otra parte, la investigación se ha nutrido de recursos metodológicos como la biografía o la antroponimia, que se presentan como fecundos instrumentos de análisis para el abordaje de la nobleza medieval. Desde una perspectiva de conjunto, la imagen que se fue construyendo en las últimas décadas en torno a la aristocracia altomedieval es la de un grupo social con una alta capacidad de reproducción social, que instrumentó estrategias de diverso carácter para desarrollar su poder en el plano material, político y simbólico. En suma, puede plantearse que la tradición historiográfica inaugurada por Bloch y Duby recogió en gran medida el legado de sus maestros en cuanto a problemáticas y esquemas interpretativos, abriéndose así líneas de investigación que profundizaron y complejizaron diversos problemas de análisis. Esto no obstó, sin embargo, para que aparecieran nuevos intereses, perspectivas de interpretación y herramientas metodológicas que renovaron y revitalizaron el estudio de la aristocracia altomedieval.

\section{COMO CITAR ESTE ARTIGO}

\section{Referência electrónica:}

PÉREZ, Mariel - "La aristocracia altomedieval: legados historiográficos y tendencias de investigación”. Medievalista [Em linha]. №15, (Janeiro - Junho 2014). [Consultado dd.mm.aaaa]. Disponível em http://www2.fcsh.unl.pt/iem/medievalista/MEDIEVALISTA15/perez1503.html.

ISSN 1646-740X. 
La aristocracia altomedieval: legados historiográficos y tendencias de investigación - Mariel Pérez

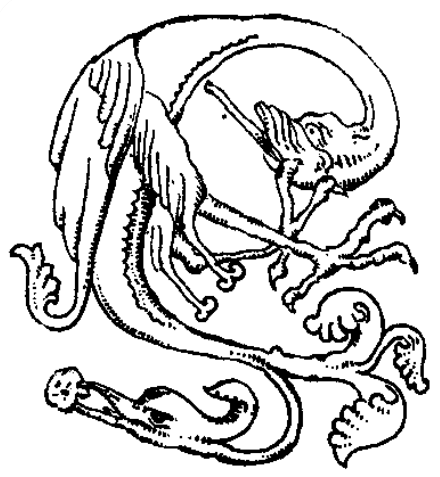

Medievalísta online $N^{\circ} 15 \mid$ Janeiro - Junho 2014 @ IEM - Instituto de Estudos Medievais 20 www2.fcsh.unl.pt/iem/medievalista 